\title{
Development and spontaneous closure of a secondary macular hole associated with submacular hemorrhage due to polypoidal choroidal vasculopathy: a case report
}

Minami Chino', Yuji Yoshikawa', Junji Kanno ${ }^{1}$, Takamitsu Nagashima ${ }^{1,2}$, Yu Sakaki ${ }^{1}$, Takeshi Katsumoto', Masayuki Shibuya', Takuhei Shoji ${ }^{1}$, Jun Makita ${ }^{1}$ and Kei Shinoda ${ }^{1 *}$

\begin{abstract}
Background: Macular hole (MH) is a retinal break in the fovea involving partial or complete dehiscence of the neural retinal layers affecting the visual quality by decreasing visual acuity (VA) and visual deformation. We describe a case of secondary $\mathrm{MH}$ associated with submacular hemorrhage $(\mathrm{SMH})$ due to polypoidal choroidal vasculopathy (PCV), which showed spontaneous closure.

Case presentation: A 67-year-old man developed decreased VA in his right eye due to an SMH. The VA was 20/50, and monthly intravitreal injection of aflibercept was administered three times. The SMH gradually decreased, and 10 months later the external limiting membrane was found to be perforated, resulting in $\mathrm{MH}$. The old clot disappeared, and the $\mathrm{MH}$ remained for 10 months. Twenty-three months later, serous retinal detachment (SRD) involving the macula appeared and the MH had disappeared. SRD gradually disappeared, and macular configuration recovered. VA gradually improved and became 20/20 38 months later.

Conclusion: Dynamic change of the ultrastructure in an unusual case of secondary-developed and spontaneously closed $\mathrm{MH}$ was clearly observed. Although the mechanism was unknown, the small diameter size and exudative PCV are thought to have contributed to the closure.
\end{abstract}

Keywords: Macular hole, Retinal displacement, Spontaneous closure, Submacular hemorrhage

\section{Background}

Macular hole $(\mathrm{MH})$ is a retinal break in the fovea involving partial or complete dehiscence of the neural retinal layers affecting the visual quality by decreasing visual acuity (VA) and visual deformation [1]. Formation of an idiopathic $\mathrm{MH}$ has been attributed to mechanical forces exerting tangential traction at the vitreomacular interface. Secondary MH may develop in association with trauma [2], macular edema [3],

\footnotetext{
*Correspondence: shinodak@med.teikyo-u.ac.jp

'Department of Ophthalmology, Faculty of Medicine, Saitama Medical University, 38 Moro-Hongo Moroyama-machi, Iruma-gun, Saitama 350-0495, Japan

Full list of author information is available at the end of the article
}

retinal detachment [4], choroidal neovascularization [5-7], or submacular hemorrhage (SMH) [8-10]. Spontaneous closure is a rare event $[7,10-16]$. We present a rare case of the development of secondary $\mathrm{MH}$ and spontaneous closure of $\mathrm{MH}$ associated with SMH due to polypoidal choroidal vasculopathy (PCV).

\section{Case presentation}

A 67-year-old man developed decreased VA in his right eye due to SMH. Fundus examination showed vitreoretinal separation and subretinal hemorrhage centering superior nasal to the optic disc and hanging over the

(c) The Author(s). 2020 Open Access This article is licensed under a Creative Commons Attribution 4.0 International License, which permits use, sharing, adaptation, distribution and reproduction in any medium or format, as long as you give appropriate credit to the original author(s) and the source, provide a link to the Creative Commons licence, and indicate if changes were made. The images or other third party material in this article are included in the article's Creative Commons licence, unless indicated otherwise in a credit line to the material. If material is not included in the article's Creative Commons licence and your intended use is not permitted by statutory regulation or exceeds the permitted use, you will need to obtain permission directly from the copyright holder. To view a copy of this licence, visit http://creativecommons.org/licenses/by/4.0/ The Creative Commons Public Domain Dedication waiver (http://creativecommons.org/publicdomain/zero/1.0/) applies to the data made available in this article, unless otherwise stated in a credit line to the data. 
macula. Fundus angiography revealed PCV (Fig. 1). The VA was 20/50 and monthly intravitreal injection of aflibercept (IVA) was administered three times. The $\mathrm{SMH}$ gradually decreased, and 10 months later the external limiting membrane (ELM) was found to be perforated, resulting in $\mathrm{MH}$ at 12 months after the initial visit. The minimum diameter of $\mathrm{MH}$ was $145 \mu \mathrm{m}$. Because the patient refused to undergo surgery, the $\mathrm{MH}$ remained for 10 months after $\mathrm{MH}$ developed. Twenty-three months after the initial visit, serous retinal detachment (SRD) involving the macula appeared and the $\mathrm{MH}$ disappeared. Fundus angiography showed moderate leakage from PCV, and IVA was performed again. Twenty-four months after the initial visit, the SRD gradually disappeared, and macular configuration recovered. During the course of the treatment, VA gradually improved and became 20/20 38 months after the initial visit (Fig. 2). The distance between the fovea and the optic disc margin before $\mathrm{MH}$ closure was $3654 \mu \mathrm{m}$. After $\mathrm{MH}$ closure, the distance was $3899 \mu \mathrm{m}$. There was no appearance of foveal displacement toward the optic disc after $\mathrm{MH}$ closure (Fig. 3).

\section{Discussion and conclusions}

We presented a rare case of development of secondary $\mathrm{MH}$ and spontaneous closure associated with $\mathrm{SMH}$ due to PCV. Two unusual findings were observed: late onset of secondary $\mathrm{MH}$ associated with SMH due to PCV and spontaneous closure and return of excellent VA.
Several macular pathologies have been reported that may develop secondary $\mathrm{MH}$ such as cystoid macular edema, subretinal fluid due to rhegmatogenous retinal detachment, and SMH [2-10]. In most of the secondary $\mathrm{MH}$ associated with $\mathrm{SMH}$, the SMH was caused by rupture of a retinal arterial macroaneurysm (RAM) [17-19]. There are several reports of secondary $\mathrm{MH}$ associated with choroidal neovascularization, but they developed after absorption of submacular fluid, not SMH [5-7]. To the best of our knowledge, this is the first report of a case of secondary $\mathrm{MH}$ associated with SMH due to PCV.

In a case of SMH due to RAM, it was considered that secondary $\mathrm{MH}$ was caused by rapid increase in intraretinal pressure (early onset) or by retinal degeneration (late onset) [18]. Sagara et al. reported that the presence of subretinal and sub-internal limiting membrane (ILM) hemorrhages after rupture of a RAM might contribute to formation of an $\mathrm{MH}$ [17].

Experimental studies on animals have also shown relationships between $\mathrm{SMH}$ and severe retinal degeneration [20, 21]. Fibrin-mediated retinal damage may be an important cause of retinal degeneration related to subretinal hemorrhage [22]. Another explanation might be that retinal inflammation was associated with the pathogenesis of MH formation as indicated by Hayashi et al. [13].

Several mechanisms for MH formation have been previously hypothesized: anteroposterior and tangential traction caused by vitreous incarceration in a needle entry site $[5,6]$, exacerbated tangential traction from contraction of the vascular membrane $[5,6]$, and critical

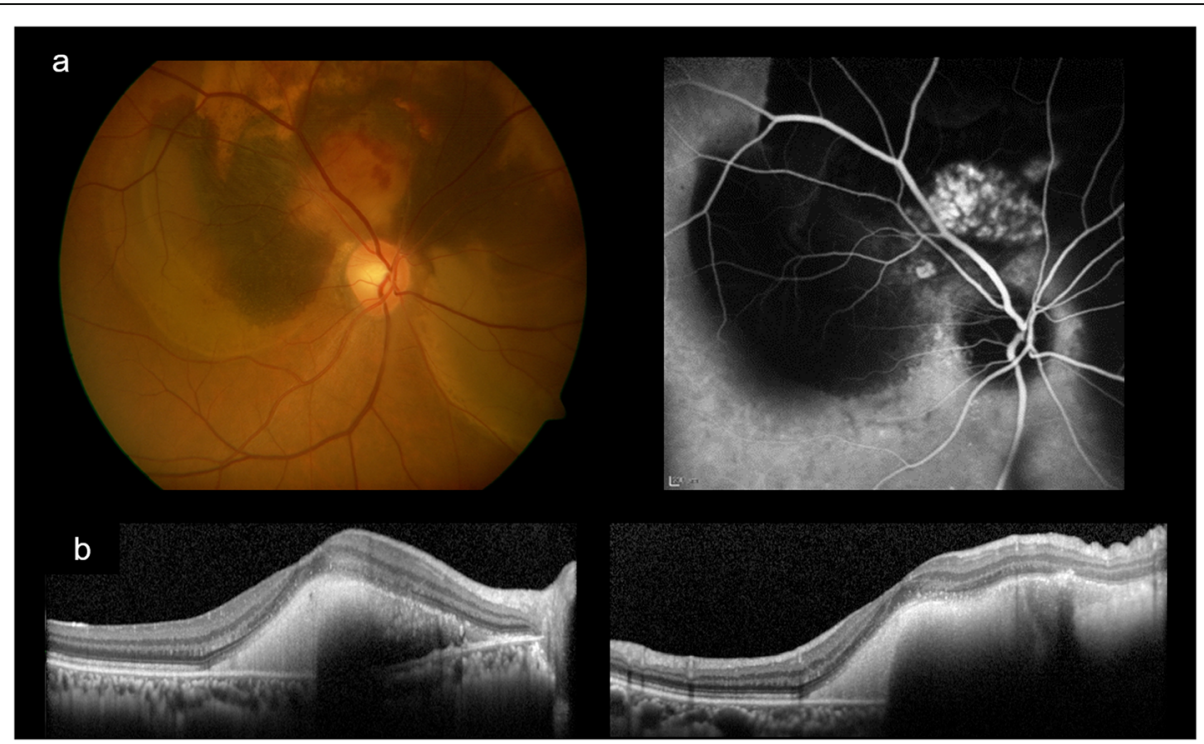

Fig. 1 Fundus appearance and angiographic findings at onset. a Fundus photograph showing subretinal hemorrhage that was centered superior nasal to the optic disc and overhung the macula. There seemed to be different regions of hemorrhage, colored yellow, bright red, and dark red. There was also serous retinal detachment surrounding the optic disc superiorly at 270 degrees. Indocyanine green fundus angiography showing leakage from multiple tufted vessels superior and superior nasal to the optic disc creating the hyperfluorescent area in the image. b Optical coherence tomography showed submacular hemorrhage without macular hole. (right; horizontal scan, left; vertical scan) 


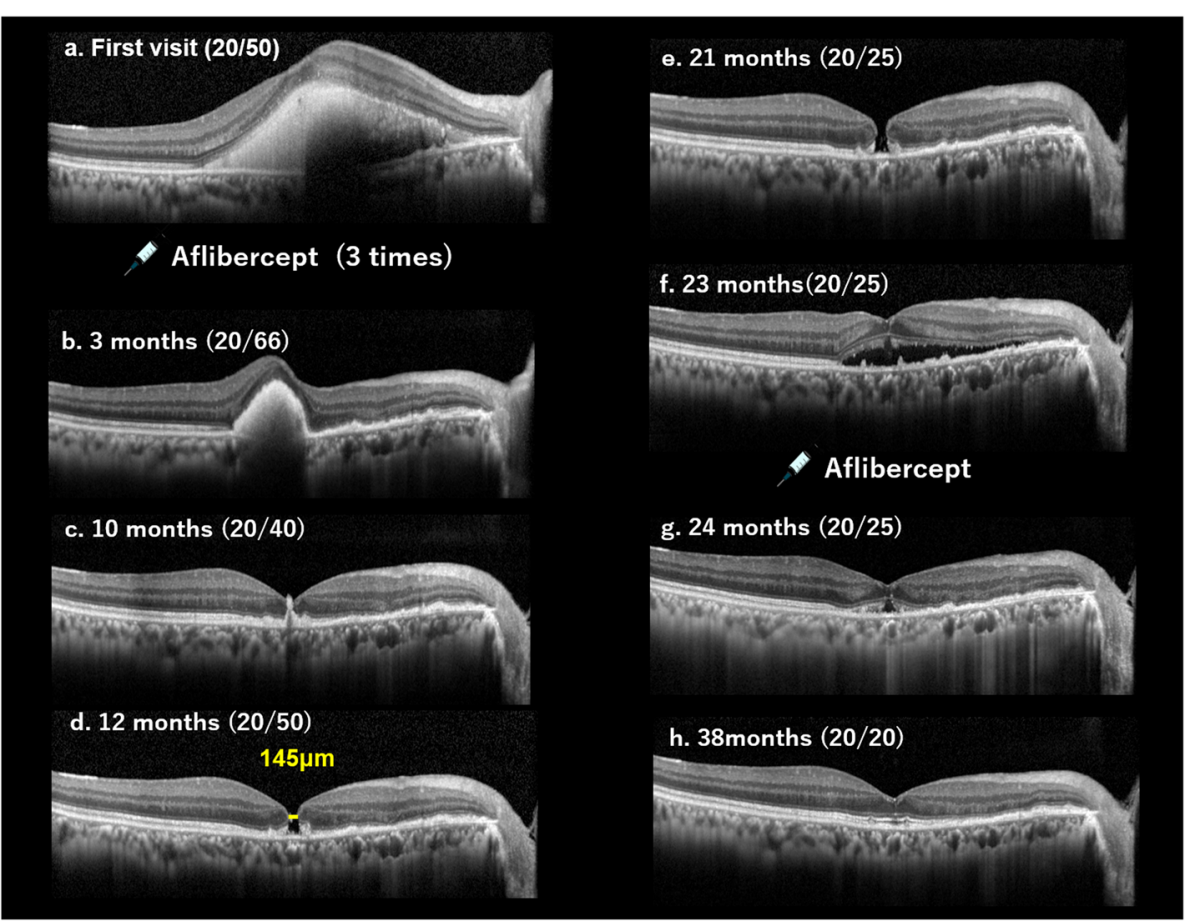

Fig. 2 Macular structure monitoring by optical coherence tomography. Optical coherence tomography (OCT) images showing the progression of macular hole formation and closure. a At first visit, OCT shows dense submacular hemorrhage (SMH). The visual acuity (VA) was 20/50. b Three months later, when monthly intravitreal injection of aflibercept (IVA) was administered three times, the SMH decreased. The VA was 20/66. c Ten months later, SMH further decreased and the external limiting membrane (ELM) was found to be perforated. The VA was 20/40. d Twelve months later, MH was observed. The minimum diameter of $\mathrm{MH}$ was $145 \mu \mathrm{m}$. The VA was 20/50. e Twenty-one months later, the MH had remained for 10 months. The VA increased to 20/25. f Twenty-three months later, serous retinal detachment (SRD) involving the macula appeared, and the MH disappeared. The VA was 20/25 and IVA was performed again. $\mathbf{g}$ Twenty-four months later, the SRD was seen to be gradually disappearing, and macular configuration had recovered. The VA was 20/ 25. $\mathbf{h}$ Thirty-eight months later, the SRD had disappeared, and the macular ultrastructure had approached to sound. The VA was 20/20

reduction in the cell-cell attachments of the retinal pigment epithelium following anti-vascular endothelial growth factor treatment [23].

In the current case, perifoveal vitreous detachment was seen on the first visit, and there was no change in the vitreoretinal interface in the course of $\mathrm{MH}$ formation. Thereafter, the $\mathrm{MH}$ appeared 12 months after the patient's first visit. Thus, we hypothesized that the process that created this $\mathrm{MH}$ (late onset) was retinal degeneration or retinal injury by $\mathrm{SMH}$.

An outstanding feature is that the patient in our case showed spontaneous $\mathrm{MH}$ closure without surgery and achieved excellent VA recovery. A previous report showed that a secondary $\mathrm{MH}$, which was associated with intravitreal injection for choroidal neovascularization (CNV), achieved closure after surgery [5]. Another study reported closure of $\mathrm{MH}$ that developed in association with $\mathrm{SMH}$ due to $\mathrm{CNV}$ or RAM achieved by vitrectomy with ILM peeling and tamponade [8,9].

Several case studies have also reported spontaneous closure of $\mathrm{MH}$ and have attributed the cause to vitreomacular traction relief over time (vitreoretinal separation), formation of bridging intraretinal tissue (due to epiretinal membrane, extension and proliferation of glial cells, or collagen secreted by glial cells), absorption of cystic space, sharp edge, inflammation, and small size of $\mathrm{MH}[1,12,16,24]$. Su et al. reported spontaneous closure of full thickness $\mathrm{MH}$ with age-related macular degeneration and suggested that the exudative process or secondary healing that stimulated adjacent glial cells contributed to $\mathrm{MH}$ closure [7]. Oliver et al. and Wang et al. reported that macular detachment, which released the retina from the retinal pigment epithelium (RPE), might have prompted approximation of the $\mathrm{MH}$ edge, thus facilitated $\mathrm{MH}$ closure $[25,26]$. In the current case, SRD, which appeared in the macular area, probably facilitated approximation of the $\mathrm{MH}$ edges by releasing the $\mathrm{MH}$ edge from the RPE. Therefore, the exudative change and accumulation of submacular fluid might have contributed to the spontaneous MH closure. Moreover, in the case of traumatic $\mathrm{MH}$, small size and absence of intraretinal cysts were predictive factors of spontaneous closure of $\mathrm{MH}$ [24]. The authors described that the presence of intraretinal cysts might be an indicator of ILM traction. In the current case, the $\mathrm{MH}$ diameter was small and there was no appearance of intraretinal cysts, both of which might be associated with spontaneous closure. 


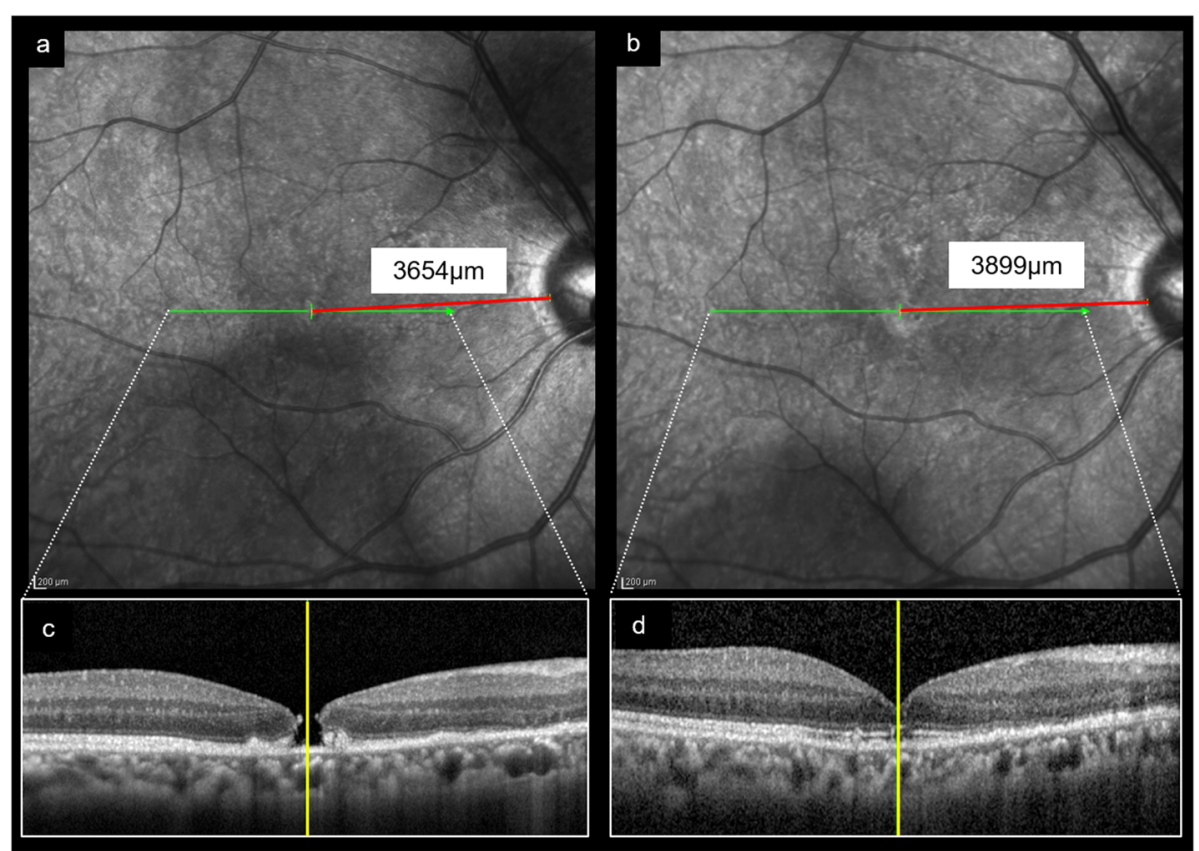

Fig. 3 Distance between the fovea and optic disc margin before and after macular hole closure. a and b; Fundus image showing the scanning line (indicated by green arrow) and the distance between the temporal disc margin and fovea (indicated by red line). The location of the fovea was determined in the B scan image as shown below. $\mathrm{c}$ and d; B scan image of the macula showing the location of the fovea (indicated by the yellow line). The distance between the fovea, which was determined by the B scan image, and the temporal optic disc margin, which was determined by large vessels, was measured on optical coherence tomography images. The distance before macular hole (MH) closure was 3654 $\mu \mathrm{m}(\mathbf{a})$. After MH closure, the distance was $3899 \mu \mathrm{m}$ (b). There was no appearance of foveal displacement toward the optic disc after MH closure

Kawano et al. reported that successful closure of $\mathrm{MH}$ by vitrectomy with ILM peeling and gas tamponade led to a displacement of the center of the macula and that eyes with spontaneous $\mathrm{MH}$ closure without surgery had no significant foveal displacement [14]. In the current case, there was no appearance of foveal displacement toward the optic disc after MH closure. Thus, we hypothesized that several factors, such as the small diameter of the $\mathrm{MH}$, absence of intraretinal cysts, and associated presence of exudation and macular detachment with PCV, contributed to the spontaneous $\mathrm{MH}$ closure but that closure was not related to the release of macular traction.

In conclusion, we presented a rare case of secondary $\mathrm{MH}$ and spontaneous closure, which was associated with $\mathrm{SMH}$ and PCV. Imaging analysis clearly illustrated the dynamic course of the formation and closing phase of the $\mathrm{MH}$. Although the precise mechanism of closure was unknown, the small size of the $\mathrm{MH}$ and exudation due to PCV are thought to have contributed to it.

\section{Abbreviations}

CNV: Choroidal neovascularization; ELM: External limiting membrane; ILM: Internal limiting membrane; IVA: Intravitreal aflibercept injection; MH: Macular hole; PCV: Polypoidal choroidal vasculopathy; RAM: Retinal arterial macroaneurysm; SMH: Submacular hemorrhage; SRD: Serous retinal detachment; VA: Visual acuity

\section{Acknowledgements}

The authors thank Editage (https://www.editage.jp) for the English language review.

\section{Authors' contributions}

$M C$ and TN cared for the patient, performed the workup, and carried out the treatment. MC, YY, and JK prepared the figures. YY, TS, YS, TK, MS, JM, and KS collected data, analyzed the ophthalmological findings, and gave critical suggestions. YY and KS prepared the manuscript. All authors agree to be accountable for all aspects of work. Patient anonymity is preserved. All authors attest that they meet the current ICMJE criteria for authorship. Al authors read and approved the final manuscript.

\section{Funding}

This study was supported in part by the Japan Society for the Promotion of Science (JSPS; KAKENHI grant number: 17 K11430). Funding was provided for English editing during manuscript preparation and for the publishing fee.

Availability of data and materials Not applicable.

Ethics approval and consent to participate

This study was approved by the ethics committee of Saitama Medical University.

\section{Consent for publication}

Written informed consent was obtained from the patient in this case report for publication of this article and any accompanying images. A copy of the written consent is available for review by the Editor of this journal.

\section{Competing interests}

The authors declare that they have no competing interests. 


\section{Author details}

'Department of Ophthalmology, Faculty of Medicine, Saitama Medical University, 38 Moro-Hongo Moroyama-machi, Iruma-gun, Saitama 350-0495, Japan. ${ }^{2}$ Kamishirane Hospital, 2-65-1, Kamishirane, Yokohama, Kanagawa 241-0002, Japan.

Received: 25 November 2019 Accepted: 4 March 2020

Published online: 17 March 2020

\section{References}

1. Duker JS, Kaiser PK, Binder S, de Smet MD, Gaudric A, Reichel E, et al. The International Vitreomacular Traction Study Group classification of vitreomacular adhesion, traction, and macular hole. Ophthalmology. 2013;120:2611-9.

2. Budoff G, Bhagat N, Zarbin MA. Traumatic macular hole: diagnosis, natural history, and management. J Ophthalmol. 2019;2019:5837832.

3. Lee YJ, Kim M. Macular hole formation after intravitreal injection of bevacizumab for diabetic macular edema. Korean J Ophthalmol. 2019;33:198-9.

4. Benzerroug M, Genevois O, Siahmed K, Nasser Z, Muraine M, Brasseur G. Results of surgery on macular holes that develop after rhegmatogenous retinal detachment. Br J Ophthalmol. 2008:92:217-9.

5. Cho JH, Park SE, Han JR, Kim HK, Nam WH. Macular hole after intravitreal ranibizumab injection for polypoidal choroidal vasculopathy. Clin Exp Optom. 2011;94:586-8

6. Querques G, Souied EH, Soubrane G. Macular hole following intravitreal ranibizumab injection for choroidal neovascular membrane caused by agerelated macular degeneration. Acta Ophthalmol. 2009:87:235-7.

7. Su D, Klufas MA, Hubschman JP. Spontaneous closure of a full-thickness macular hole with conversion to exudative age-related macular degeneration. JAMA Ophthalmol. 2016;134:604-6.

8. Bakri SJ, Sears JE, Lewis H. Management of macular hole and submacular hemorrhage in the same eye. Graefes Arch Clin Exp Ophthalmol. 2007;245: 609-11.

9. Kawaji T, Takasu I, Takano A, Sato T, Hashida M. Internal limiting membrane peeling-repositioning technique for macular hole after macular hemorrhage associated with rupture of retinal arterial macroaneurysm. Retina. 2019;39: S84-6.

10. Uemoto R, Mizuki N. Spontaneous closure of a macular hole caused by a ruptured retinal arterial macroaneurysm. Eur J Ophthalmol. 2008;18:462-5.

11. Lee J, Nguyen VQ, Doss MK, Eller AW. Spontaneous closure of a chronic full thickness macular hole after failed surgery. Am J Ophthalmol Case Rep. 2019:13:59-61.

12. Hamano R, Shimoda Y, Kishi S. Tomographic features of spontaneous closure of full-thickness macular holes. Jpn J Ophthalmol. 2007;51:76-7.

13. Hayashi I, Shinoda H, Nagai N, Tsubota K, Ozawa Y. Retinal inflammation diagnosed as an idiopathic macular hole with multiple recurrences and spontaneous closures: a case report. Medicine. 2019;98:e14230.

14. Kawano K, Ito Y, Kondo M, Ishikawa K, Kachi S, Ueno S, et al. Displacement of foveal area toward optic disc after macular hole surgery with internal limiting membrane peeling. Eye. 2013;27:871-7.

15. Yamashita T, Uemara A, Uchino E, Doi N, Ohba N. Spontaneous closure of traumatic macular hole. Am J Ophthalmol. 2002;133:230-5.

16. Liang $X$, Liu W. Characteristics and risk factors for spontaneous closure of idiopathic full-thickness macular hole. J Ophthalmol. 2019;2019:4793764.

17. Sagara N, Kawaji T, Koshiyama Y, Inomata Y, Fukushima M, Tanihara H. Macular hole formation after macular haemorrhage associated with rupture of retinal arterial macroaneurysm. Br J Ophthalmol. 2009;93:1337-40.

18. Sato R, Yasukawa T, Hirano Y, Ogura Y. Early-onset macular holes following ruptured retinal arterial macroaneurysms. Graefes Arch Clin Exp Ophthalmol. 2008:246:1779-82

19. Tashimo A, Mitamura Y, Ohtsuka K, Okushiba U, Imaizumi H, Takeda M. Macular hole formation following ruptured retinal arterial macroaneurysm. Am J Ophthalmol. 2003;135(4):487-92.

20. Toth CA, Morse LS, Hjelmeland LM, Landers MB. Fibrin directs early retinal damage after experimental subretinal hemorrhage. Arch Ophthalmol. 1991;109:723-9.

21. Lewis H, Resnick SC, Flannery JG, Straatsma BR. Tissue plasminogen activator treatment of experimental subretinal hemorrhage. Am J Ophthalmol. 1991;111:197-204

22. McCabe CM, Flynn HW, McLean WC, Brod RD, McDonald HR, Johnson MW, et al. Nonsurgical management of macular hemorrhage secondary to retinal artery macroaneurysms. Arch Ophthalmol. 2000;118:780-5.
23. Carvounis PE, Kopel AC, Benz MS. Retinal pigment epithelium tears following ranibizumab for exudative age-related macular degeneration. Am J Ophthalmol. 2007;143:504-5.

24. Chen $\mathrm{H}$, Chen W, Zheng $\mathrm{K}$, Peng $\mathrm{K}$, Xia H, Zhu L. Prediction of spontaneous closure of traumatic macular hole with spectral domain optical coherence tomography. Sci Rep. 2015;5:12343.

25. Oliver A, Wojcik EJ. Macular detachment for treatment of persistent macular hole. Ophthalmic Surg Lasers Imaging. 2011;42:516-8.

26. Wong R, Howard C, Orobona GD. Retina expansion technique for macular hole apposition report 2: efficacy, closure rate, and risks of a macular detachment technique to close large full-thickness macular holes. Retina. 2018;38:660-3.

\section{Publisher's Note}

Springer Nature remains neutral with regard to jurisdictional claims in published maps and institutional affiliations.
Ready to submit your research? Choose BMC and benefit from:

- fast, convenient online submission

- thorough peer review by experienced researchers in your field

- rapid publication on acceptance

- support for research data, including large and complex data types

- gold Open Access which fosters wider collaboration and increased citations

- maximum visibility for your research: over $100 \mathrm{M}$ website views per year

At $\mathrm{BMC}$, research is always in progress.

Learn more biomedcentral.com/submissions 